\title{
The high resistance of bacteria to clindamycin and cefepime: a call to revisit antibiotics reserved for use at tertiary hospitals in Tanzania
}

\section{Wigilya P. Mikomangwa ( $\square$ wpad.miko@gmail.com )}

Muhimbili University of Health and Allied Sciences

\section{George M. Bwire}

Muhimbili University of Health and Allied Sciences

Manase Kilonzi

Muhimbili University of Health and Allied Sciences

Hamu Mlyuka

Muhimbili University of Health and Allied Sciences

\section{Ritah Mutagonda}

Muhimbili University of Health and Allied Sciences

\section{Wema Kibanga}

Muhimbili University of Health and Allied Sciences

\section{Alphonce Ignace Marealle}

Muhimbili University of Health and Allied Sciences

\section{Omary Minzi}

Muhimbili University of Health and Allied Sciences

Kennedy D. Mwambete

Muhimbili University of Health and Allied Sciences

\section{Research}

Keywords: Antibiotic resistance, clindamycin, cefepime, meropenem, reserved antibiotics, bacteria, susceptibility pattern

Posted Date: January 2nd, 2020

DOl: https://doi.org/10.21203/rs.2.19863/v1

License: (c) (7) This work is licensed under a Creative Commons Attribution 4.0 International License. Read Full License 


\section{Abstract}

Background Antibiotic resistance poses burden to the community and health care services. Efforts are being made at local, national and global level to combat the rise of antibiotic resistance including antibiotic stewardship. Surveillance to antibiotic resistance is of importance to aid in planning and implementing infection prevention and control measures. The study was conducted to assess the resistance pattern to cefepime, clindamycin and meropenem, which are reserved antibiotics for use at tertiary hospitals in Tanzania

Methods A Hospital-based antibiotic resistance surveillance was conducted between July and November 2019 using 201 consecutively selected clinical isolates at Muhimbili National Hospital and Bugando Medical Center, Tanzania. All organisms isolated were identified based on colony morphology, Gram staining and relevant biochemical tests. Antibiotic susceptibility testing was performed on Muller-Hinton agar using Kirby-Bauer disc diffusion method. Antibiotic susceptibility on the selected antibiotic discs (cefepime, clindamycin and meropenem) was performed according to the protocol by National Committee for Clinical Laboratory Standards.

Results A total of 201 clinical samples were tested in this study. Urine $(39.8 \%, n=80)$ and blood $(35.3 \%$, $\mathrm{n}=71)$ accounted for most of the collected samples followed by pus $(16.9 \%, \mathrm{n}=34)$. The overall bacterial resistance to clindamycin, cefipime and meropenem was $70.1 \%, 72.4 \%$ and $8.5 \%$ respectively. Most (88.9\%) of Enterococcus spp were resistant to clindamycin. About $68.4 \%$ Staphylococcus aureus isolates were resistant to clindamycin whereby $56.3 \%, 75.6 \%, 93.8 \%$ and $100 \%$ of the tested Escherichia coli , Klebsiella spp, Pseudomonas aeruginosa and Enterobacter cloacae respectively, were cefepime resistant. About $8.5 \%$ of isolated Klebsiella spp were resistant and $6.4 \%$ had intermediate susceptibility to meropenem. Also, Pseudomonas aeruginosa was resistant by $31.2 \%$ and $25 \%$ had intermediate susceptibility to meropenem. All Acinetobacter baumannii and Proteus spp (both $100.0 \%, n=4$ ) were susceptible to meropenem.

Conclusion The overall bacterial resistance to clindamycin and cefepime is high and low in meropenem. Henceforth, culture and susceptibility results should be used to guide the use of these antibiotics. Antibiotics with low resistance rate should be introduced to the reserve category and continuous antibiotic surveillance is warranted.

\section{Background}

Antibiotic resistance is rising to a dangerous level and is a global concern; bacteria are adapting new resistance mechanisms and spreading them across the species and geographical location, thus threatening over-decade achievement to treat common infectious diseases $(1,2)$. Antibiotic resistance is associated with prolonged length of hospital stay, increased treatment cost, morbidity and mortality $(1,3,4)$. Recent data shows that, worldwide, more than 700,000 people die annually because of resistant superbugs and the trend is expected to reach 10 million deaths per annum in 2050 (5). In the USA, more 
than 2.8 million people were infected by severe antibiotic resistant infections, and more than 35000 die from these infections every year (6). The problem is even worse in developing countries. For instance, in 2012, approximately 19400 and 56500 neonates in Nigeria and India respectively died from severe antibiotic-resistant pathogens (3). Also, antibiotics resistance has immense negative effect on the economy. It is estimated that, by 2030 if it is left unaddressed the world will incur annual cost of about 1 trillion US\$ (7).

In 2017, the World Health Organization (WHO) published the list of most evolving bacteria which are the leading the cause of health care facility acquired infection worldwide and pose great threat to the public health in general; Enterococcus spp., Staphylococcus aureus, Klebsiella pneumoniae, Acinetobacter baumannii, Pseudomonas aeruginosa, and Escherichia coli, collectively termed ESKAPE (3).

A growing list of infections such as urinary tract infections, pneumonia, bloodstream infections, reproductive tract infections, and foodborne diseases are becoming harder, and sometimes impossible to treat as antibiotics become less effective $(1,2,8)$. Where antibiotics can be bought for human or animal use without a prescription, the emergence and spread of resistance is made worse $(3,9)$. Similarly, in countries without standard treatment guidelines, antibiotics are often overprescribed by health workers and veterinarians and over-used by the public. In addition, over prescription of antibiotics has been mentioned to be the significant contributor of antibiotic resistance (10).

In 2019 the WHO established a model list of essential medicines in which antibiotics are included (11). The categories establish the antibiotics to be prescribed at different levels of health care facilities; access group (dispensaries, health centers), watch group (council hospitals) and reserved group (tertiary hospitals such as national, zonal, and specialized hospitals) (11). The reserved antibiotics play as the last weapon when all other antibiotics have failed. Grouping of antibiotics in respective categories is country specific. The Tanzanian Ministry responsible for health implemented the recommendations through the National Essential Medicine List (NEMLIT) (12). The Ministry has created the reserve group that consists of cefepime, clindamycin and meropenem.

Several studies have reported the failure of clindamycin, cefepime and meropenem in different parts of the world $(3,4,13)$. For example, in Africa $70 \%$ of $\mathrm{E}$. coli and $77 \%$ of $\mathrm{K}$. pneumonia from clinical isolates were resistant to third generation cephalosporin. Invasive isolate from Europe indicated about $8 \%$ of $\mathrm{K}$. pneumonia, $19 \%$ of P.aeroginosa and $56 \%$ of A.baumannii isolated from blood and cerebral spinal fluid were resistant to carbapenem. In 2009, Mshana et al, reported inducible resistance to occur in MRSA isolated at Bugando Medical Center (BMC), Tanzania; about 61\% (16/26) of MRSA exhibited inducible clindamycin resistance (14). Tanzania has also reported resistance to meropenem from clinical isolates particular Pseudomonas spp (15). Since categorizing of clindamycin, cefepime and meropenem in 2017 to reserve group, information on the susceptibility profile is scarce. Therefore, regular surveillance on the resistance profile of antibiotics is required to plan and implement infection prevention and control measures. 


\section{Methods}

The study was conducted in two tertiary teaching hospitals namely Muhimbili National Hospital (MNH) and Bugando Medical Center (BMC) located at Dar es Salaam and Mwanza regions in Tanzania. MNH is a National Referral Hospital and University Teaching Hospital with 1,500-bed facility, attending 1,000 to 1,200 outpatients per week, admitting 1,000 to 1,200 inpatients per week. The diagnostic laboratory department at $\mathrm{MNH}$ is the leading diagnostic laboratory in Tanzania. Bugando Medical Centre (BMC) representing Zonal hospital has 950-bed capacity, serves a population of about 16 million people and attends around 300,000 patients each year. Both MNH and BMC clinical microbiology laboratories are accredited with the international standard ISO 15189:2007. The study was conducted between July and November 2019. A total of 201 consecutively selected clinical isolates were studied for susceptibility with special focus to clindamycin, meropenem and cefepime. Apart from assessing the susceptibility pattern of the three antibiotics, the socio-demographic and clinical information on the microbiological request form were documented on the case report form (CRF).

\section{Laboratory Procedures}

\section{Gram stain, culture and identification}

This was performed at the respective hospital (MNH \& BMC) where organism from the clinical samples was isolated, cultured and identified according to their laboratory protocol. Direct Gram stain films were performed to examine the presence of microorganisms in the sample. Depending on the nature of the sample (throat swab, urine, stool, blood or sputum) microbiological culture was performed using appropriate culture media and conditions as per microbiology laboratory protocol. All organisms isolated were identified based on colony morphology, Gram staining and relevant biochemical tests $(16,17)$.

\section{Antibiotic susceptibility testing}

Antibiotic susceptibility testing was performed on Muller-Hinton agar using Kirby-Bauer disc diffusion method at BMC and MNH clinical microbiology laboratory. Antibiotic susceptibility on the selected antibiotic discs; cefepime $(30 \mu \mathrm{g})$, clindamycin $(2 \mu \mathrm{g})$ and meropenem $(10 \mu \mathrm{g})$, was performed according to the protocol by Clinical and Laboratory Standards (CLSI) (18).

Interpretation and Reporting of the Results

Using the published CLSI guidelines, the susceptibility or resistance of the organism to each drug tested was determined (18). For each drug, the zone size was indicated on the recording sheet as susceptible $(\mathrm{S})$, intermediate $(\mathrm{I})$, or resistant $(\mathrm{R})$ based on the interpretation chart (16).

\section{Quality Control}

The American Type Culture Collection (ATCC) standard bacteria corresponding to each 
clinical isolate was used as control microorganisms for instance (18).

\section{Data analysis}

The collected microbiological information, socio-demographic and clinical data were extracted from the CRF to Microsoft excel, coded and analyzed using Statistical Package for Social Sciences (SPSS) version 23. The frequency distribution and proportion of identified bacteria per type of sample collected were summarized. The proportion of resistant bacteria per antibiotic (clindamycin, cefepime and meropenem) was determined. Patients' age (in years) was categorized as $\leq 12$ (children) and $>12$ (adult) as per MNH and BMC admission criteria. The differences in proportion of categorical variables were compared by Fisher's exact or Pearson's Chi-Square test. The two tailed p-value of less than 0.05 was considered statistically significant.

\section{Results}

\section{Socio-demographic and clinical information}

Overall $51.4 \%$ were male patients with age above 12 years old ( $57.9 \%$ ). More than $20 \%$ of patients had fever, $6.6 \%$ had infected wound (either injury, at incision site or abdomen burst post-surgery) abdominal pain and difficulty in breathing (both 3.8\%), dysuria, cough and cardiac diseases (each 3.3\%). Also, anemia, sepsis and vomiting (each $2.7 \%$ ) were reported (Table 1).

\section{Type of samples used and culture results}

A total of 201 clinical samples was involved in this study. Urine $(39.8 \%, n=80)$ and blood $(35.3 \%, n=71)$ accounted for most of the collected samples followed by pus $(16.9 \%, n=34)$. Most of the blood samples were collected from children (46.8\%) than adults (27.4\%) ( $p$-value $<0.001)$. High proportion of pus $(22.6 \%)$ and sputum (9.4\%) samples were collected from adults while $48.1 \%$ of urine sample were collected from children ( $p$-value $<0.001)$. The one throat swab sample was collected from a child.

Most (64.2\%) of clinical isolates were found to be Gram negative strains. The distribution of type of strain (Gram negative or positive) did not differ by age groups ( $p$-value $=0.88$ ). The most identified bacteria were S. aureus (28.4\%), Klebsiella spp (23.4\%), followed by Escherichia coli (17.9\%). Staphylococcus aureus $(56.3 \%)$ was the leading bacteria isolated from blood followed by Klebsiella spp (22.5\%) while E. coli was highly (32.5\%) found in urine samples. The highest proportion (38.5\%) of Pseudomonas aeruginosa was found in sputum samples (Table 2).

\section{Resistance patterns of the tested bacteria}

\section{Resistance to clindamycin}


The Gram positive pathogens tested for susceptibility were Enterococcus Spp, S. aureus and Streptococcus pyogen. The overall proportion Gram positive pathogens resistant to clindamycin was $70.1 \%$ (Figure 1). Whereby $88.9 \%(n=9)$ of Enterococcus Spp and $68.4 \%(n=57)$ of $S$. aureus were resistant to clindamycin.

\section{Resistance to cefepime}

The total of 132 bacterial isolates were subjected to susceptibility test against cefepime. The overall proportion of Gram negative bacteria resistant to cefepime was $72.4 \%$ (Figure 1). Only $15.4 \%$ of isolates were susceptible to cefepime. Of 45 Klebsiella spp were tested for susceptibility to cefepime, $75.6 \%$ were resistant and only $11.1 \%$ were susceptible. Whereas, 32 isolates of $E$. coli tested for susceptibility to cefepime; $56.3 \%$ were resistant and $21.9 \%$ were susceptible. Also, sixteen (16) P. aeruginosa isolated were tested for susceptibility to cefepime of which $93.8 \%$ were found to be resistant. Fourteen (14) Citrobacter spp, were tested by which $85.7 \%(\mathrm{n}=14)$ were resistant. We found that, all five Enterobacter cloacae tested (100\%) were resistant. Only four (4) A. baumannii were isolated and tested for susceptibility to cefepime, $3(75 \%)$ of which were resistant (Table 3$)$.

\section{Resistance to meropenem}

Furthermore, the Gram negative bacteria $(n=128)$ isolated from clinical samples were tested for susceptibility against meropenem. Most of the pathogens were meropenem susceptible (85.3\%), however, $8.5 \%$ of pathogens were found resistant (Figure 1). The isolated Klebsiella spp $(\mathrm{n}=47)$ were tested for susceptibility to meropenem, of which $8.5 \%$ were resistant and $6.4 \%$ had intermediate susceptibility; one K.oxytoca and two K.pneumonia were resistant. Of $\mathrm{n}=16$ P. aeruginosa isolated $31.2 \%$ were resistant and 25\% had intermediate susceptibility. All A.baumannii and Proteus spp (both $100.0 \%, \mathrm{n}=4$ ) were susceptible to meropenem (Table 3)

\section{Discussion}

This study describes the resistance profile of clindamycin (lincosamide), cefepime (fourth generation cephalosporin) and meropenem (carbapenem). In 2017 these antibiotics were reserved for use at tertiary hospitals following the WHO recommendation as a key focus to antibiotic stewardship (12,19). The study found the overall resistance to clindamycin, cefipime and meropenem to be $70.1 \%, 72.4 \%$ and $8.5 \%$ respectively, which was higher than previous studies conducted in Tanzania $(14,15,20)$.

The study also found resistant pathogenic bacteria in the collected samples as previously reported by Nyambura et al, who did the study at BMC (20). Sadly, most of the blood samples collected in this study had resistant S. aureus which was suggestive of bloodstream infection as evidenced by more than $18 \%$ of patients who had fever. It has been documented that, S.aureus was the leading cause of blood stream infection acquired in hospital settings (21-23). S.aureus get access to blood through intravascular devices such as central venous catheters, peripheral intravenous catheters, arterial catheters and urinary catheter $(21,22)$. Thus presence of such microorganisms that are introduced through invasive procedures 
such as incision, intubation, puncture, and drug injections could greatly contribute to long hospital stays as results of bacteremia(21). Bloodstream infection have been reported to be more common among children similar to our study $(22,23)$.

Bloodstream infection is associated with high mortality rate, morbidity and prolonged hospital stay making the treatment more complicated in face of increased resistant $S$. aureus $(21,24)$. Our study found $68.4 \%$ of tested S.aureus were resistant similar to Mshana et al, study in 2009 that found $61 \%$ of MRSA were resistant to clindamycin (14). Clindamycin is one of the potential alternative in high prevalent MRSA infections (25). The observed increased proportion of resistance could suggest extensive use of the antibiotic that leads to increase in resistance with time (26). In this study, Enterococcus spp isolates were found in urine and blood samples thus posing risk for development of urinary tract and bloodstream infections respectively similar to what has been reported previously(20). Most (88.9\%) of the Enterococcus spp were resistant to clindamycin similar to the study by Azin et al who found the $96 \%$ resistance to clindamycin in Iran (27). It has been documented that the Enteroccoci are intrinsically resistant to clindamycin, which could explain the observed resistant pattern $(8,28)$. Being normal flora of the gastrointestinal tract with frequent contact to antibiotics which are, in high rate misused, could increase the proportion of resistant Enterococci $(9,29,30)$. Also, the previous use of clindamycin as additive drug to quinine for treatment of uncomplicated malaria in pregnant could have accelerated the resistance of this antibiotic (31).

Most of the Gram negative pathogens in this study were resistant to cefipime which is the fourth cephalosporin generation antibiotic for instance, 75.6\% Klebsiella Spp, 93.8\% P. aeruginosa, 75.0\% A.baumannii, and $56.3 \%$ E.coli were resistant. This pattern of resistance is comparable to the previous study that was conducted at BMC, the proportion of resistant Gram negative bacteria was $80.6 \%, 87.5 \%$ and $63.2 \%$ in the order of Klebsiella spp, P.aeruginosa, 56.3\% E.coli (20). The slight observed difference in proportion could be attributed to the difference in generations of cephalosporin used. Their study assessed the susceptibility of Gram negative bacteria using third generation cephalosporin (ceftriaxone/cefotaxime)(20), contrary to our study in which we used fourth generation cephalosporin (cefepime). Indeed, the observed high proportion of resistant bacteria was almost similar to the overall proportion of resistant Gram negative bacteria to third generation cephalosporin in Africa (3). These bacteria are among the most mutating bacteria with high risk to human health $(1,32)$. The high proportion of resistant Gram negative bacteria to fourth generation cephalosporin (cefepime) could be suggestive of bacteria adaptive mechanisms by cross-resistance between generations of the same antibiotic class (32). The overuse and irrational use of antibiotics especially third generation cephalosporin (ceftriaxone) could contribute to failure of subsequent cephalosporin generations $(29,30,33)$.

Pseudomonas aeruginosa and Klebsiella spp were isolated in all samples, this could have contributed to bloodstream infection, wound infection, urinary tract and respiratory tract infections as previously described. About $31.2 \%$ of the tested $P$. aeruginosa isolates were meropenem resistant contrary to the study by Sabrina et al who reported $8.9 \%$ of resistant Pseudomonas aeruginosa. Their study was conducted between 2010-2011, more than eight years ago. The trend of increasing resistant 
P.aeruginosa was noted in a study that evaluated clinical isolated at BMC from 2007 to 2012 that found the prevalence of resistant P.aeruginosa to be 19.5\% (15). A systematic review on antibiotic resistance in Africa found P.aeruginosa to be one of the bacteria resistant to carbapenem (34). The trend of increasing bacteria strains resistant to meropenem is threatening since this drug serve as the last weapon for most of Gram negative bacteria resistant to the commonly used antibiotics.

Furthermore, we found meropenem resistant Klebsiella spp to be $8.5 \%$ which was higher than the previous study by Martha et al (1.5\%) who conducted the study at BMC (15). The increase in proportion of resistant P. aeruginosa and Klebsiella Spp could indicate heightening of antibiotic resistance with time necessitating questioning the effectiveness of the control measures in place. High susceptibility observed to some of pathogenic bacteria such as A.baumannii and Proteus spp could indicate good performance in some bacteria though the increasing resistance to some highly mutating bacteria is warranting strict control measures. Carbapenems are considered the treatment of choice and last option for the common nosocomial infection caused by $P$. aeruginosa resistant to other $\beta$-lactam antibiotics (35). Inappropriate use of antibiotics such as carbapenems especially in private health facilities could increase the prevalence of resistant bacteria to carbapenems; pressure from pharmaceutical companies and intending to make profit could be contributing factors (36-38) .

\section{Limitations}

This study is one of few studies conducted in East Africa that assessed the resistance pattern of clindamycin, cefepime and meropenem, however, most of the previous studies did not include cefepime which is the fourth generation cephalosporin and clindamycin(34,35), hence the current susceptibility pattern of these antibiotics has limited index comparator. Our study aimed at evaluating the current status of antibiotic resistance burden in our settings after the implementation of WHO stewardship program of reserving some antibiotics to be used as last resort when multidrug resistant infection is encountered. Therefore, we focused only to survey the resistant pattern of clindamycin, cefepime and meropenem. Being a cross-sectional design, the clinical outcomes of patients from which the resistant bacteria were isolated were not documented, therefore these findings should be interpreted with cautions because they don't equate to clinical outcomes. Furthermore, whether the infection was community or hospital acquired was not evaluated. The mechanisms of resistance and the molecular markers were not the scope of this study. In addition, this study was conducted at two tertiary teaching hospitals excluding other tertiary hospitals in the country hence should be generalized with high precaution.

\section{Conclusion}

High resistance to clindamycin and cefepime was revealed in this study. Meropenem resistant to P. aeruginosa and Klebsiella Spp was also observed. In addition, the pathogenic bacteria of high priority (ESKAPE) were resistant to all studied antibiotics at variable proportion. We recommend routine culture and susceptibility testing for proper use of these antibiotics as well as searching for new antibiotics. Since clindamycin and cefepime are becoming obsolete, the Ministry responsible for Health should 
reconsider classifying these two antibiotics as reserve antibiotics. Taking into account that the resistance to antibiotics can assume uneven geographical distribution; either a national or zonal antibiotic resistance surveillance center should be established. The studied center (s) may serve as reference for monitoring the trend of antibiotic resistance as receive patients from different parts of the country and thus aid in planning and implementing control measures that may be stratified region.

\section{Abbreviations}

ESKAPE: Enterococcus spp., Staphylococcus aureus, Klebsiella pneumoniae, Acinetobacter baumannii, Pseudomonas aeruginosa, and Escherichia coli, NEMLT: National Essential Medicine List, MRSA: methicillin resistant Staphylococcus aureus, BMC: Bugando Medical Center; MNH: Muhimbili National Hospital

\section{Declarations}

Ethics approval and consent to participate

Approval to conduct this study was sought from the Ethical Committee of Muhimbili University of Health and Allied Sciences. In addition, permission was requested from the appropriate authorities of $\mathrm{MNH}$ and $\mathrm{BMC}$ to conduct the study at their facilities.

Consent for publication

Not applicable

Availability of data and material

The dataset generated and/or analyzed during this study is available from the corresponding author upon reasonable request.

Competing interests

The authors declare that they have no competing interests

Funding

This study was funded by the Swedish International Development Cooperation Agency-Sida through Muhimbili University of Health and Allied Sciences (MUHAS), through Sida-small grant program coordinated by the MUHAS Director of Research and Publication. The funder did not participate in the design, analysis, interpretation or manuscript preparation.

Authors' contributions 
WPM, MK, GMB designed the study and coordinated data collection. WPM conducted data analysis and drafted the manuscript. GMB, MK conceptualized the study. WPM, MK, WK, HM, AIM, RM, OM, KM and GMB participated in, interpretation of data and manuscript development. All authors read and approved the final manuscript.

\section{Acknowledgements}

We highly appreciate the contribution from Nyanda Shango and his colleagues at BMC microbiology laboratory together with James Kalabashanga from $\mathrm{MNH}$ for their technical expertise during the phase of data collection.

Authors' information (optional)

${ }^{1}$ Department of Clinical Pharmacy and Pharmacology, Muhimbili University of Health and Allied Sciences, Dar-es-Salaam, Tanzania

${ }^{2}$ Department of Pharmaceutical Microbiology, Muhimbili University of Health and Allied Sciences

\section{References}

1. Levy SB, Marshall B. Antibacterial resistance worldwide: causes, challenges and responses. Nat Med. 2004;10(12):S122-9.

2. Wormser GP, Bergman MM. The Antibiotic Paradox: How the Misuse of Antibiotics Destroys Their Curative Powers, 2nd Edition By Stuart B. Levy Cambridge, Massachusetts: Perseus Publishing, 2002. 376 pp., illustrated. \$17.50 (paper). Clin Infect Dis. 2003 Jan 15;36(2):238.

3. Geneva. Prioritization of pathogens to guide discovery, research and development of new antibiotics for drug-resistant bacterial infections, including tuberculosis. World Heal Organ. 2017;12.

4. Hawkey PM, Warren RE, Livermore DM, McNulty CAM, Enoch DA, Otter JA, et al. Treatment of infections caused by multidrug-resistant gram-negative bacteria: Report of the British society for antimicrobial chemotherapy/healthcare infection society/british infection association joint working party. J Antimicrob Chemother. 2018;73(March 2015):iii2-78.

5. Roope LSJ, Smith RD, Pouwels KB, Buchanan J, Abel L, Eibich P, et al. The challenge of antimicrobial resistance: What economics can contribute. Science (80- ). 2019;364.

6. Frieden T. Antibiotic resistance threats in the United States. Centers Dis Control Prev. 2013;114.

7. Berthe, Franck Cesar Jean; Wadsworth, Jonathan; Thiebaud, Alessia; Marquez, Patricio V.; Baris E.

Pulling Together to Beat Superbugs Knowledge and Implementation Gaps in Addressing Antimicrobial Resistance. HNP/Agriculture Glob Antimicrob Resist Initiat Washington, DC World Bank Gr. 2019;

8. Cardoso T, Ribeiro O, Aragão IC, Costa-Pereira A, Sarmento AE. Additional risk factors for infection by multidrug-resistant pathogens in healthcare-associated infection: A large cohort study. BMC Infect 
Dis. $2012 ; 12$.

9. Laxminarayan R, Matsoso P, Pant S, Brower C, Røttingen J-A, Klugman K, et al. Access to effective antimicrobials: a worldwide challenge. Lancet (London, England). 2016 Jan 9;387(10014):168-75.

10. Payne LE, Gagnon DJ, Riker RR, Seder DB, Glisic EK, Morris JG, et al. Cefepime-induced neurotoxicity: a systematic review. Crit Care. 2017 Nov 14;21(1):276.

11. WHO. World health organization model list of essential medicines. Ment Holist Heal Some Int Perspect. 2019;119-34.

12. Ministry of Health and Social Welfare. Standard treatment guidelines \& national essential medicines list, Tanzania mainland G. 2017. 47 p.

13. Lambert ML, Suetens C, Savey A, Palomar M, Hiesmayr M, Morales I, et al. Clinical outcomes of health-care-associated infections and antimicrobial resistance in patients admitted to European intensive-care units: A cohort study. Lancet Infect Dis. 2011;11(1):30-8.

14. Mshana SE, Kamugisha E, Mirambo M, Chalya P, Rambau P, Mahalu W. Prevalence of clindamycin inducible resistance among methicillin-resistant Staphylococcus aureus at Bugando Medical Centre, Mwanza , Tanzania. 2009;11(2):59-64.

15. Mushi MF, Mshana SE, Imirzalioglu C, Bwanga F. Carbapenemase Genes among Multidrug Resistant Gram Negative Clinical Isolates from a Tertiary Hospital in Mwanza, Tanzania. 2014;2014.

16. Collee, J.G., Miles, R.S. and Watt B. Tests for the Identification of Bacteria. In: Collee, J.G., Marmion, B.P., Fraser, A.G. and Simmons, A., Eds., Mackie \& McCartney Practical Medical Microbiology. 14th Edition, Churchill Livingstone, New York; 1996. p. 131-51.

17. Şimşek S, Yurtseven N, Gerçekogalu H, Izgi F, Sohtorik Ü, Canik S, et al. Ventilator-associated pneumonias in a cardiothoracic surgery centre postoperative intensive care unit. J Hosp Infect. 2001 Apr 1;47(4):321-4.

18. M02-A12: Performance Standards for Antimicrobial Disk Susceptibility Tests; Approved StandardTwelfth Edition. 2015.

19. Organization WH. WHO Model List of Essential Medicines. World Heal Organ [Internet]. 2013; (October):1-43. Available from:

http://www.who.int/medicines/organization/par/edl/expcom13/eml13_en.pdf

20. Moremi N, Claus H, Mshana SE. Antimicrobial resistance pattern : a report of microbiological cultures at a tertiary hospital in Tanzania. BMC Infect Dis. 2016;1-7.

21. Bartlett JG. Nosocomial bloodstream infections in US hospitals: Analysis of 24,179 cases from a prospective nationwide surveillance study. Infect Dis Clin Pract. 2004;12(6):376.

22. Bai Y, Zheng Z, Du M, Yao H, Liu Y, Suo J. Bloodstream Infection and Its Clinical Characteristics and Relevant Factors Associated with Interventional Therapy in a Large Tertiary Hospital: A Six Years Surveillance Study. Biomed Res Int. 2019;2019.

23. Mhada T V, Fredrick F, Matee MI, Massawe A. Neonatal sepsis at Muhimbili National Hospital, Dar es Salaam, Tanzania; aetiology, antimicrobial sensitivity pattern and clinical outcome. BMC Public 
Health. 2012;12(1):904.

24. Karchmer AW. Nosocomial Bloodstream Infections: Organisms, Risk Factors, and Implications. Clin Infect Dis. 2000 Sep 1;31(Supplement_4):S139-43.

25. Fokas S, Fokas S, Tsironi M, Kalkani M, Dionysopouloy M. Prevalence of inducible clindamycin resistance in macrolide-resistant Staphylococcus spp. Clin Microbiol Infect. 2005 Apr 1;11(4):33740.

26. Odsbu I, Khedkar S, Lind F, Khedkar U, Nerkar SS, Orsini N, et al. Trends in resistance to extendedspectrum cephalosporins and carbapenems among escherichia coli and klebsiella spp. Isolates in a district in Western India during 2004-2014. Int J Environ Res Public Health. 2018;15(1):1-15.

27. Sattari-Maraji A, Jabalameli F, Node Farahani N, Beigverdi R, Emaneini M. Antimicrobial resistance pattern, virulence determinants and molecular analysis of Enterococcus faecium isolated from children infections in Iran. BMC Microbiol. 2019;19(1):156.

28. Kristich CJ, Rice LB, Arias CA. Enterococcal Infection - Treatment and Antibiotic Resistance Molecular Mechanisms of Antibiotic Resistance in Enterococci. 2014;1-31.

29. Sonda TB, Horumpende PG, Kumburu HH, van Zwetselaar M, Mshana SE, Alifrangis M, et al. Ceftriaxone use in a tertiary care hospital in Kilimanjaro, Tanzania: A need for a hospital antibiotic stewardship programme. PLoS One. 2019;14(8):1-11.

30. Mboya EA, Sanga LA, Ngocho JS. Irrational use of antibiotics in the moshi municipality Northern Tanzania: A cross sectional study. Pan Afr Med J. 2018;31:1-10.

31. Edition TUR of TSTG and EMLM of H and SWF. the United Republic of Tanzania Standard Treatment Guidelines and Essential Medicines List Ministry of Health and Social Welfare Fourth Edition. 2013. 42-43 p.

32. Santajit S, Indrawattana N. Mechanisms of Antimicrobial Resistance in ESKAPE Pathogens. Biomed Res Int. 2016;2016.

33. Wangai FK, Masika MM, Lule GN, Karari EM, Maritim MC, Jaoko WG, et al. Bridging antimicrobial resistance knowledge gaps: The East African perspective on a global problem. PLoS One. 2019;14(2):1-12.

34. Tadesse BT, Ashley EA, Ongarello S, Havumaki J, Wijegoonewardena M, González IJ, et al. Antimicrobial resistance in Africa: A systematic review. BMC Infect Dis. 2017;17(1):1-17.

35. Ssekatawa K, Byarugaba DK, Wampande E, Ejobi F. A systematic review: The current status of carbapenem resistance in East Africa. BMC Res Notes. 2018;11(1):1-9.

36. Yan K, Xue M, Ye D, Yang C, Chang J, Jiang M, et al. Antibiotic prescribing practices in secondary and tertiary hospitals in Shaanxi province, western China, 2013-2015. PLoS One. 2018;13(12):2013-5.

37. Sharma M, Eriksson B, Marrone G, Dhaneria S, Lundborg CS. Antibiotic prescribing in two private sector hospitals; one teaching and one non-teaching: A cross-sectional study in Ujjain, India. BMC Infect Dis. 2012;12. 
38. Landstedt K, Sharma A, Johansson F, Stålsby Lundborg C, Sharma M. Antibiotic prescriptions for inpatients having non-bacterial diagnosis at medicine departments of two private sector hospitals in Madhya Pradesh, India: a cross-sectional study. BMJ Open. 2017 Apr 1;7(4):e012974.

\section{Tables}

Table 1. Socio-demographic and clinical characteristics of patients from which the samples were collected.

\begin{tabular}{|c|c|c|}
\hline Variable & Frequency & Percentage (\%) \\
\hline \multicolumn{3}{|l|}{ Patient category ${ }^{\mathrm{a}}$} \\
\hline Adult & 106 & 52.7 \\
\hline \multicolumn{3}{|l|}{ Sex ${ }^{a}$} \\
\hline Male & 94 & 46.8 \\
\hline Female & 89 & 44.3 \\
\hline \multicolumn{3}{|l|}{ Place of residence ${ }^{b}$} \\
\hline Urban & 76 & 37.8 \\
\hline Rural & 18 & 9.0 \\
\hline \multicolumn{3}{|c|}{ Comorbidities/symptoms/signs ${ }^{\square}$} \\
\hline abdominal pain & 8 & 3.9 \\
\hline anemia & 5 & 2.5 \\
\hline breast swelling & 2 & 1.0 \\
\hline heart disease & 8 & 3.9 \\
\hline chronic kidney disease & 3 & 1.5 \\
\hline congenital pneumonia & 2 & 1.0 \\
\hline convulsion & 2 & 1.0 \\
\hline cough & 7 & 3.5 \\
\hline diarrhea & 4 & 2.0 \\
\hline difficulty in breathing & 7 & 3.5 \\
\hline diabetes mellitus & 2 & 1.0 \\
\hline dysuria & 6 & 3.0 \\
\hline ear swelling & 2 & 1.0 \\
\hline fever ${ }^{\ddagger}$ & 37 & 18.4 \\
\hline hematuria & 2 & 1.0 \\
\hline HIV & 3 & 1.5 \\
\hline joint pain & 3 & 1.5 \\
\hline sickle cell disease & 3 & 1.5 \\
\hline sepsis & 5 & 2.5 \\
\hline skin rash & 2 & 1.0 \\
\hline TB & 2 & 1.0 \\
\hline UTI & 3 & 1.5 \\
\hline vomiting & 5 & 2.5 \\
\hline wound infection & 12 & 6.0 \\
\hline vaginal discharge & 2 & 1.0 \\
\hline Others ${ }^{\square}$ & 13 & 6.5 \\
\hline undocumented $\mathbb{Z}$ & 54 & 26.5 \\
\hline
\end{tabular}


${ }^{a}$ Few laboratory request form did not have information on age or sex (both $\left.n=18\right)$

${ }^{b}$ Some place of residence was not documented for some patients $(n=107)$

$\ddagger$ Most of the comorbidities were accompanied with fever, however, some were documented fever alone.

Abbreviations: TB, tuberculosis; UTI, urinary tract infection; HIV, human immunodefiency virus.

खUndocumented comorbidies, signs or symptoms accounted for $26.5 \%(n=54)$

هOthers such as amenorrhea, burn, cloudy urine, eclampsia, chest pain, lower limb edema, lung cancer, malaria, nasal bleeding, nephritis, peritonitis, urethral itching, (each $n=1)$

\section{Table 2. Bacterial isolates distribution by specimens}

\begin{tabular}{|c|c|c|c|c|c|}
\hline Identified bacteria & $\begin{array}{l}\text { Blood: } n=71 \\
n(\%)\end{array}$ & $\begin{array}{l}\text { Pus: } n=34 \\
n(\%)\end{array}$ & $\begin{array}{l}\text { Sputum, } n=13 \\
n(\%)\end{array}$ & $\begin{array}{l}\text { Urine: } n=80 \\
n(\%)\end{array}$ & $\begin{array}{l}\text { Total }^{\ddagger \#} \\
n=201 \\
n(\%)\end{array}$ \\
\hline Acinetobacter baumannii & $2(2.8)$ & $1(2.9)$ & $0(0.0)$ & $1(1.3)$ & $4(2.0)$ \\
\hline Citrobacter spp $p^{a}$ & $1(1.4)$ & $4(11.8)$ & $1(7.7)$ & $10(12.5)$ & $16(8.0)$ \\
\hline Escherichia coli & $0(0.0)$ & $9(26.5)$ & $1(7.7)$ & $26(32.5)$ & $36(17.9)$ \\
\hline Enterobacter cloacae & $3(4.2)$ & $0(0.0)$ & $0(0.0)$ & $2(2.5)$ & $5(2.5)$ \\
\hline Enterococcus spp $p^{b}$ & $4(5.6)$ & $1(2.9)$ & $0(0.0)$ & $9(11.3)$ & $14(7.0)$ \\
\hline Klebsiella $s p p^{c}$ & $16(22.5)$ & $6(17.6)$ & $3(23.1)$ & $22(27.5)$ & $47(23.4)$ \\
\hline Pseudomonas aeruginosa & $5(7.0)$ & $3(8.8)$ & $5(38.5)$ & $3(3.8)$ & $16(8.0)$ \\
\hline Proteus spp $p^{d}$ & $0(0.0)$ & $3(8.8)$ & $0(0.0)$ & $1(1.3)$ & $4(2.0)$ \\
\hline Staphylococcus aureus & $40(56.3)$ & $7(20.6)$ & $3(23.1)$ & $6(7.5)$ & $57(28.4)$ \\
\hline Other spp $p^{e}$ & $0(0.0)$ & $0(0.0)$ & $0(0.0)$ & $0(0.0)$ & $2(1.0)$ \\
\hline
\end{tabular}

${ }^{a}$ Citrobacter spp; Citrobacter freundi $(\mathrm{n}=5)$, Citrobacter koseri $(\mathrm{n}=4)$, unidentified Citrobacter Spp $(\mathrm{n}=7)$

${ }^{\mathrm{b}}$ Enterococcus spp; Enterococcus faecalis $(\mathrm{n}=1)$, Enterococcus aerogenes $(\mathrm{n}=5)$, unidentified Enterococcus spp $(\mathrm{n}=8)$. 
${ }^{\mathrm{C} K l e b s i e l l a}$ spp; Klebsiella oxytoca $(\mathrm{n}=8)$, Klebsiella pneumoniae $(\mathrm{n}=26)$, unidentified Klebsiella Spp $(n=13)$.

d Proteus spp; Proteus Mirabilis ( $\mathrm{n}=2)$, Proteus vulgaris $(\mathrm{n}=2)$.

eStreptococcus pyogen $(\mathrm{n}=1)$ and Shigella $\operatorname{spp}(\mathrm{n}=1)$ were isolated from throat swab and stool respectively.

$\neq \neq$ Samples not included in the table $(n=3)$; stool, throat swab and urethral swab (each $n=1)$.

Table 3. Susceptibility pattern of tested bacteria to cefepime, meropenem and clindamycin

\begin{tabular}{|c|c|c|c|c|c|c|c|c|c|}
\hline \multirow[t]{2}{*}{$\sqrt{\text { bacteria }}$} & \multicolumn{3}{|c|}{ Cefepime n(\%) } & \multicolumn{3}{|c|}{ Meropenem, n(\%) } & \multicolumn{3}{|c|}{ Clindamycin n(\%) } \\
\hline & $\mathrm{S}$ & $\mathrm{I}$ & $\mathrm{R}$ & $\mathrm{S}$ & 1 & $\mathrm{R}$ & $\mathrm{S}$ & 1 & $\mathrm{R}$ \\
\hline $\begin{array}{l}\text { obacter } \\
\text { innii }\end{array}$ & $\begin{array}{l}1 \\
(25.0)\end{array}$ & $\begin{array}{l}0 \\
(0.0)\end{array}$ & $\begin{array}{l}3 \\
(75.0)\end{array}$ & $\begin{array}{l}4 \\
(100.0)\end{array}$ & $\begin{array}{l}0 \\
(0.0)\end{array}$ & $\begin{array}{l}0 \\
(0.0)\end{array}$ & NA & NA & NA \\
\hline zcter spp & $\begin{array}{l}2 \\
(12.5)\end{array}$ & $\begin{array}{l}2 \\
(12.5)\end{array}$ & $\begin{array}{l}12 \\
(75.0)\end{array}$ & $\begin{array}{l}15 \\
(93.8)\end{array}$ & $\begin{array}{l}0 \\
(0.0)\end{array}$ & $\begin{array}{l}1 \\
(6.3)\end{array}$ & NA & NA & NA \\
\hline ichia coli & $\begin{array}{l}7 \\
(21.9)\end{array}$ & $\begin{array}{l}7 \\
(21.9)\end{array}$ & $\begin{array}{l}18 \\
(56.3)\end{array}$ & $\begin{array}{l}35 \\
(97.2)\end{array}$ & $\begin{array}{l}0 \\
(0.0)\end{array}$ & $\begin{array}{l}1 \\
(2.8)\end{array}$ & NA & NA & NA \\
\hline $\begin{array}{l}\text { bacter } \\
e\end{array}$ & $0(0.0)$ & $\begin{array}{l}0 \\
(0.0)\end{array}$ & $\begin{array}{l}5 \\
(100.0)\end{array}$ & $\begin{array}{l}4 \\
(80.0)\end{array}$ & $\begin{array}{l}1 \\
(20.0)\end{array}$ & $\begin{array}{l}0 \\
(0.0)\end{array}$ & NA & NA & NA \\
\hline coccus spp & $\begin{array}{l}1 \\
(20.0)\end{array}$ & $\begin{array}{l}0 \\
(0.0)\end{array}$ & $\begin{array}{l}4 \\
(80.0)\end{array}$ & $\begin{array}{l}5 \\
(100.0)\end{array}$ & $\begin{array}{l}0 \\
(0.0)\end{array}$ & $\begin{array}{l}0 \\
(0.0)\end{array}$ & $\begin{array}{l}1 \\
(11.1)\end{array}$ & 0 & $\begin{array}{l}8 \\
(88.9)\end{array}$ \\
\hline ella spp & $\begin{array}{l}5 \\
(11.1)\end{array}$ & $\begin{array}{l}6 \\
(13.3)\end{array}$ & $\begin{array}{l}34 \\
(75.6)\end{array}$ & $\begin{array}{l}40 \\
(85.1)\end{array}$ & $\begin{array}{l}3 \\
(6.4)\end{array}$ & $\begin{array}{l}4 \\
\text { (8.5) }\end{array}$ & NA & NA & NA \\
\hline yinosa & $1(6.3)$ & $\begin{array}{l}0 \\
(0.0)\end{array}$ & $\begin{array}{l}15 \\
(93.8)\end{array}$ & $\begin{array}{l}7 \\
(43.8)\end{array}$ & $\begin{array}{l}4 \\
(25.0)\end{array}$ & $\begin{array}{l}5 \\
(31.3)\end{array}$ & NA & NA & NA \\
\hline$s s p p$ & $\begin{array}{l}2 \\
(50.0)\end{array}$ & $\begin{array}{l}0 \\
(0.0)\end{array}$ & $\begin{array}{l}2 \\
(50.0)\end{array}$ & $\begin{array}{l}4 \\
(100.0)\end{array}$ & $\begin{array}{l}0 \\
(0.0)\end{array}$ & $\begin{array}{l}0 \\
(0.0)\end{array}$ & $\begin{array}{l}17 \\
(29.8)\end{array}$ & $1(1.8)$ & $\begin{array}{l}39 \\
(68.4)\end{array}$ \\
\hline us & $0(0.0)$ & $\begin{array}{l}0 \\
(0.0)\end{array}$ & $\begin{array}{l}4 \\
(100.0)\end{array}$ & $\begin{array}{l}2 \\
(50.0)\end{array}$ & 0 & $\begin{array}{l}2 \\
(50.0)\end{array}$ & NA & NA & NA \\
\hline$a s p p$ & $\begin{array}{l}1 \\
(100.0)\end{array}$ & $\begin{array}{l}0 \\
(0.0)\end{array}$ & $0(0.0)$ & $\begin{array}{l}1 \\
(100.0)\end{array}$ & $\begin{array}{l}0 \\
(0.0)\end{array}$ & $\begin{array}{l}0 \\
(0.0)\end{array}$ & NA & NA & NA \\
\hline roccus & NA & NA & NA & NA & NA & NA & $0(0.0)$ & $\begin{array}{l}1 \\
(100.0)\end{array}$ & $0(0.0)$ \\
\hline
\end{tabular}

Abbreviations: S, susceptibe; I, intermediate; R, resistant; spp, species, NA, isolated bacteria were not tested on the respective antibiotic 
Figures

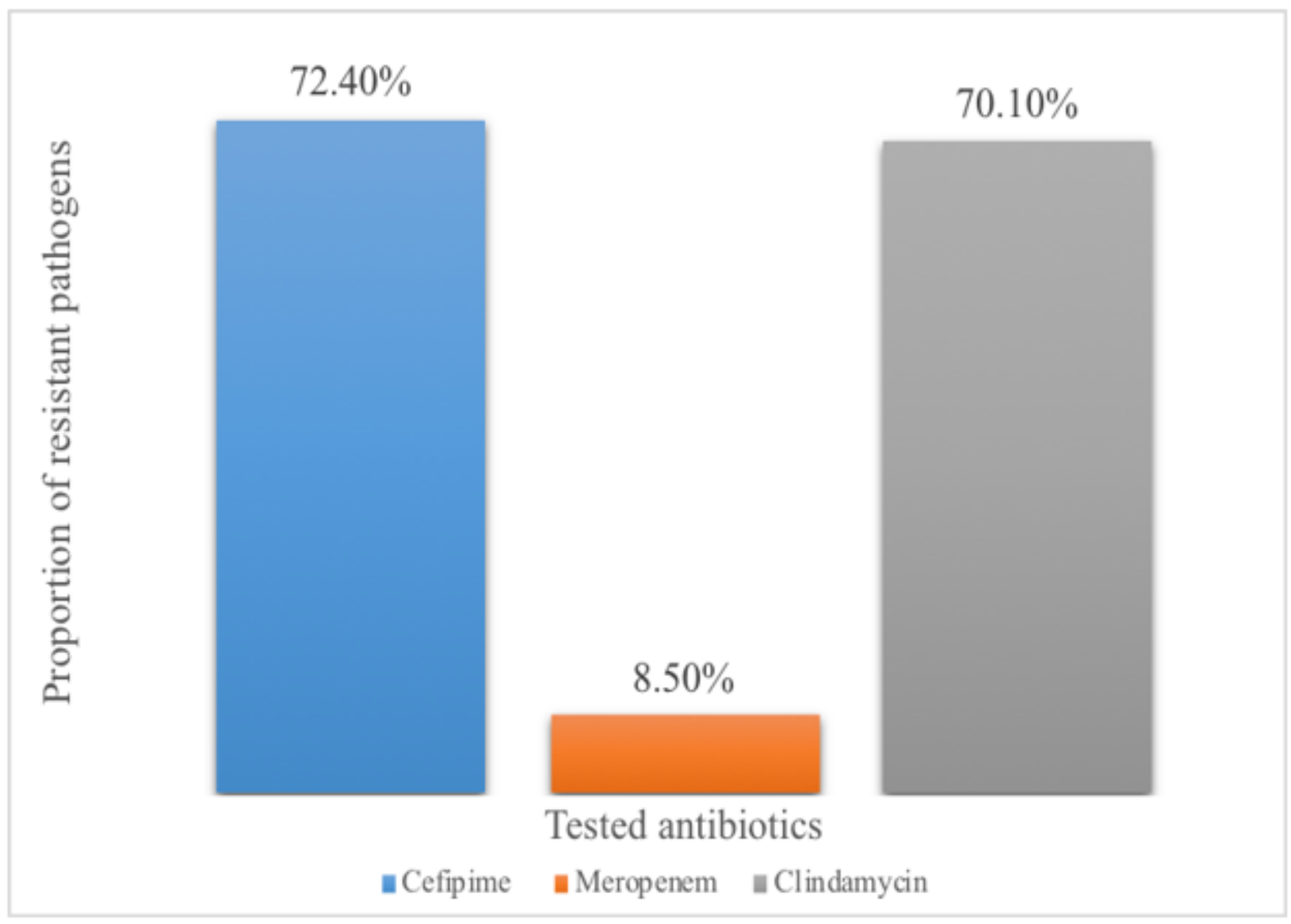

Figure 1

Proportion of pathogens resistant to cefepime, meropenem and clindamycin 